\title{
Artigo Técnico \\ ESTUDO DA COAGULAÇÃO APLICADA À FILTRAÇÃO DIRETA DESCENDENTE
}

\section{EVALUATING COAGULATION APPLIED TO DIRECT DOWNFLOWING FILTRATION}

\section{Eliane Prado Cunha Costa dos Santos}

Engenheira Civil e Mestre em Saneamento, Meio Ambiente e Recursos Hídricos pela UFMG

\section{ANA RAQUEL TEIXEIRA}

Engenheira Civil e Mestre em Saneamento, Meio Ambiente e Recursos Hídricos pela UFMG

\author{
CRistina Pogglati Almeida \\ Bióloga (Instituto Isabela Hendrix)
}

\begin{abstract}
MARCELO LIBÂNIO
Engenheiro Civil e Mestre em Engenharia Sanitária (UFMG), Doutor em Hidráulica e Saneamento (USP) e Professor Adjunto do Departamento de Engenharia Hidráulica e Recursos Hídricos da UFMG
\end{abstract}

\section{VALTER LÚCIO DE PÁDUA}

Engenheiro Civil (UFMG), Mestre e Doutor em Hidráulica e Saneamento (USP) e Professor Adjunto do Departamento de Engenharia Sanitária e Ambiental da UFMG

Recebido: 25/04/06 Aceito: 11/04/07

\section{RESUMO}

Neste trabalho compara-se o desempenho dos coagulantes Cloreto Férrico, Sulfato de Alumínio, Sulfato Férrico e Hidróxi-Cloreto de Alumínio - isoladamente ou combinados com polímeros catiônicos - na redução da cor aparente, turbidez e fitoplâncton visando ao tratamento por filtração direta descendente. Os ensaios foram realizados em reatores estáticos e em unidade piloto, empregando água captada em reservatório de acumulação. Os resultados obtidos com os coagulantes analisados nas dosagens recomendadas para filtração direta forneceram valores de cor aparente e turbidez em acordo com a Portaria 518/2004 do Ministério da Saúde. Não foi significativa a diferença, para o nível de significância de $5 \%$, entre os coagulantes testados em escalas de bancada e piloto.

PALAVRAS-CHAVE: Coagulação, filtração direta, tratamento de água.

\section{INTRODUÇÃO}

A coagulação consiste no conjunto de açôes físicas e reaçôes químicas, com duração de poucos segundos, entre o coagulante, usualmente um sal de alumínio ou de ferro, a água e as impurezas presentes. Apresenta-se em três fases: (i) formação das espécies hidrolisadas do sal quando disperso na água, (ii) desestabilização das partículas coloidais e suspensas dispersas na massa líquida e (iii) agregação dessas partículas para formação dos flocos.

\begin{abstract}
The present work compares several coagulants (alum, ferric chloride, ferric sulfate, and aluminum hydrochloride - each by itself or with cationic polymers) applied to in line downflowing direct filtration, as to their effectiveness in reducing apparent color, turbidity, and phytoplankton. The tests were carried out in static reactors and in a pilot unit, using natural water drawn from the reservoir of a water treatment plant. Coagulants used in dosages recommended for direct filtration yielded values of apparent color and turbidity that complied with Brazilian government regulations. There was no significant difference among them in either bench or pilot scale at a 95\% reliability interval.
\end{abstract}

KEYWORDS: Coagulation, direct filtration, water treatment.
Diversos fatores interferem no processo de coagulação, destacando-se o $\mathrm{pH}$ e a alcalinidade da água bruta, a natureza das partículas coloidais, o tamanho das partículas e o tipo e a dosagem dos produtos químicos aplicados. Também influem, em menor grau, a concentração e a idade da solução de coagulante, a temperatura e, dependendo do mecanismo de coagulação predominante, o gradiente de velocidade e o tempo de agitação na unidade de mistura rápida.
Cleasby et al (1989) apud Budd et al (2004), analisando estações de tratamento que empregavam filtração em meio granular nos EUA, concluíram que, para se atingir metas de remoção de partículas, o processo de coagulação foi mais importante do que as próprias características físicas dos filtros. Os mesmos autores enfatizaram que a qualidade da água tratada acaba por depender mais da eficácia da estratégia do tratamento químico e da habilidade dos operadores em responder a even- 
tuais problemas, do que da sofisticação ou da idade das estaçóes de tratamento.

A definição do tipo de coagulante a ser utilizado deve levar em conta os seguintes critérios: sua adequabilidade à água bruta; a tecnologia de tratamento empregada; o custo do coagulante propriamente dito; o custo dos produtos químicos porventura associados - alcalinizantes, ácidos ou auxiliares de coagulação; e o custo e manutenção dos tanques e dosadores.

Um outro aspecto que vem sendo considerado para a escolha do coagulante em diversos países refere-se às características do lodo gerado no tratamento, as quais dependem da qualidade da água bruta e do pré-tratamento químico utilizado. Segundo a AWWA (1990), os dois componentes principais dos resíduos do tratamento de água (RTA) são os materiais contidos na água - solúveis ou insolúveis - e os produtos utilizados para a remoção destes materiais. As características químicas e físicas dos RTA variam conforme a composição química do coagulante. Conseqüentemente, problemas relacionados com o manuseio, tratamento e disposição dos RTA podem ser minimizados ajustando-se o processo de coagulação e, em alguns casos, pela mudança do coagulante.

Segundo DeWolf et al (2003), o desempenho da coagulação pode apresentar diferenças quando se utilizam coagulantes de mesmo nome, porém fornecidos por empresas diferentes. Isso se deve à variação das concentrações de impurezas no material utilizado em sua produção.

Identificam-se como principais características dos coagulantes:

- concentração em termos de ingrediente ativo (e.g., $\% \mathrm{Al}_{2} \mathrm{O}_{3}, \% \mathrm{Fe}$ ou \% $\mathrm{Fe}_{2} \mathrm{O}_{3}$ );

- acidez como porcentagem de ácido livre ou pré-neutralização como porcentagem de basicidade;

- concentração de contaminantes (e.g. material inerte, carbono orgânico total - COT, metais e outros);

- temperatura de cristalização e congelamento, no caso de países frios;

- corrosividade e compatibilidade com os materiais onde serão armazenados e tubulaçōes onde serão transportados;

- viscosidade;

- efeitos da diluição sobre a atividade, viscosidade e temperatura de cristalização;
- custo, facilidade de transporte, armazenamento e manuseio;

- características do lodo gerado; e

- compatibilidade com outros produtos químicos utilizados no tratamento de água.

Dentre os mecanismos de coagulação, pode-se citar o de varredura e o de adsorsão/neutralização de cargas. O mecanismo de varredura é utilizado para tecnologias convencionais, ou de ciclo completo, que incluem as seguintes etapas de tratamento: coagulação, floculação, decantação e filtração. Os flocos formados no mecanismo de coagulação por varredura deverão apresentar densidade suficiente para permitir sua deposição nos decantadores.

Já o mecanismo de adsorção/neutralização de cargas é utilizado em tecnologias de tratamento simplificadas, como, por exemplo, a filtração direta, na qual a água é coagulada e depois filtrada. Nesse mecanismo ocorre a neutralização das cargas das partículas presentes na água bruta, não havendo necessidade de se formar flocos grandes e sim de desestabilizar as partículas para que estas sejam mais eficientemente retidas nos filtros. Assim, as dosagens de coagulante utilizadas tendem a ser inferiores às necessárias no mecanismo de coagulação por varredura.

O emprego da filtração direta tem como vantagem a significativa redução dos custos de implantação e operação, devido à ausência de unidades de decantação e às menores dosagens de produtos químicos necessárias à coagulação, em função do mecanismo utilizado. Dessa forma, reduz-se, por vezes em até $50 \%$, a área necessária à construção da estação, e em até $70 \%$ o volume de lodo gerado (Kawamura, 1991).

Em um estudo realizado no Canadá, os custos operacionais de uma estação de filtração direta de escoamento descendente foram comparados com os de uma estação convencional, concluindo-se que, na potabilização de águas de cor verdadeira e turbidez baixas, a primeira apresentou economia anual na operação da ordem de $50 \mathrm{mil}$ dólares, para uma produção equânime de $1,6 \mathrm{~m}^{3} / \mathrm{s}$.

Nessa pesquisa os autores inferiram também que uma dosagem baixa de coagulante aumenta a chance de sucesso do tratamento por filtração direta. Assim sendo, recomendam que quando a dosagem requerida é inferior a $6 \mathrm{mg} / \mathrm{L}$, a água torna-se, em geral, ade- quada à filtração direta. Se a dosagem ficar entre 6 e $15 \mathrm{mg} / \mathrm{L}$, a água estaria numa faixa intermediária e a tecnologia de tratamento por filtração direta deve ser avaliada caso a caso. Finalmente, se a dosagem superar $20 \mathrm{mg} / \mathrm{L}$, questiona-se o uso da filtração direta (Wagner e Hudson Jr., 1982), a menos que se preveja o emprego da dupla filtração.

A comparação da eficiência dos coagulantes visando ao tratamento por filtração direta tem sido o foco de várias pesquisas. Ndiongue et al (2000) realizaram ensaios de jar test com o objetivo de comparar o desempenho de coagulantes no tratamento, por filtração direta, de água com turbidez menor ou igual a 2,5 uT e carbono orgânico dissolvido menor ou igual a $2,58 \mathrm{mg} / \mathrm{L}$. Foram estudados o Sulfato Silicato Polialumínio, o HidróxiCloreto de Alumínio (PACl), o Sulfato de Alumínio, o Sulfato Férrico préhidrolisado e o Cloreto Férrico. Todos os coagulantes utilizados foram capazes de reduzir a turbidez. Entre aqueles a base de alumínio, o $\mathrm{PACl}$ pareceu ser o mais efetivo, enquanto, dentre aqueles a base de ferro, o Cloreto Férrico foi o melhor. Embora as dosagens do Sulfato de Alumínio fossem 1,2 $\mathrm{mg} \mathrm{Al}^{+3} / \mathrm{L}$ mais altas do que as dos outros coagulantes a base de alumínio, ele ofereceu uma vantagem comercial sobre os mesmos por causa do baixo custo. Quando a turbidez de 0,1 uT foi alcançada, a quantidade de carbono orgânico dissolvido removido era baixa. $\mathrm{O}$ maior percentual de remoção, de $23 \%$, foi obtido com Cloreto Férrico.

Por fim, Sens et al (2002) apud Di Bernardo (Coord.) et al (2003), em estudos comparando PACl 10,5\% $\mathrm{Al}_{2} \mathrm{O}_{3}$ com basicidade de $68 \%$ com Sulfato de Alumínio 14,5\% $\mathrm{Al}_{2} \mathrm{O}_{3}$, observaram maior estabilidade da qualidade da água filtrada produzida com o uso do $\mathrm{PACl}$, diante da alteração do pH de coagulação ao longo das carreiras de filtração. A coagulação definida em jar test para ocorrer em $\mathrm{pH}=6 \pm 0,05$ não apresentou perturbações quando o $\mathrm{pH}$ oscilou em torno de $6 \pm 0,25$.

\section{OBJETIVO}

Este trabalho visa comparar a eficiência de diferentes tipos de coagulantes - isoladamente e associados a polímeros catiônicos - no tratamento por filtração direta em linha de escoamento descendente, utilizando água natural captada 
em reservatório de acumulação; avaliar a influência da mudança de escala de bancada para escala piloto na obtenção de parâmetros operacionais da coagulação e, por fim, estimar a duração das carreiras de filtração em escala real para uma ETA cujos filtros funcionam com taxa declinante variável.

\section{METODOLOGIA}

\section{Equipamentos e coagulantes utilizados}

Além da vidraria e materiais utilizados nos experimentos, foram empregados: (i) potenciômetro marca Quimis; (ii) espectrofotômetro modelo DR/2000, marca $\mathrm{HACH}$; (iii) turbidímetro modelo $2100 \mathrm{~N}$, marca HACH; (iv) equipamento de jar test Nova Ética modelo LDB. Para os ensaios de contagem de fitoplâncton, utilizou-se bomba a vácuo para separar as amostras e microscópio Olimpus BX 50 com câmara de Sedgwick-Rafter para a contagem.

Ao equipamento de jar test foram adaptados seis filtros em tubo de PVC com diâmetro de $12,7 \mathrm{~mm}$ e $20 \mathrm{~cm}$ de comprimento, contendo areia para simular o tratamento por filtração direta. $\mathrm{Na}$ parte inferior de cada filtro de bancada foi fixado um cap acoplado a um tubo de cobre com diâmetro interno de $4 \mathrm{~mm}$ e uma tela de latão com abertura de $0,4 \mathrm{~mm}$. A geratriz superior do tubo de cobre situava-se $15 \mathrm{~cm}$ acima da base do filtro (Figura 1).

Os coagulantes testados estão caracterizados na Tabela 1. Avaliaram-se dois tipos de Sulfato de Alumínio, de fornecedores diferentes.

\section{Caracterização da água bruta}

A caracterização da água utilizada nos ensaios foi realizada por meio de dados operacionais de uma estação de tratamento de água (ETA) localizada na região metropolitana de Belo Horizonte, cuja vazão afluente média é de $1 \mathrm{~m}^{3} / \mathrm{s}$, mesmo local onde foi construída a instalação piloto. Foram contemplados os seguintes parâmetros: cor aparente, turbidez, $\mathrm{pH}$, alcalinidade total e fitoplâncton por mililitro, referentes aos anos de 2000 a 2003, fornecidos pela concessionária, e dados obtidos durante realização dos ensaios. Para todos os parâmetros medidos fo-

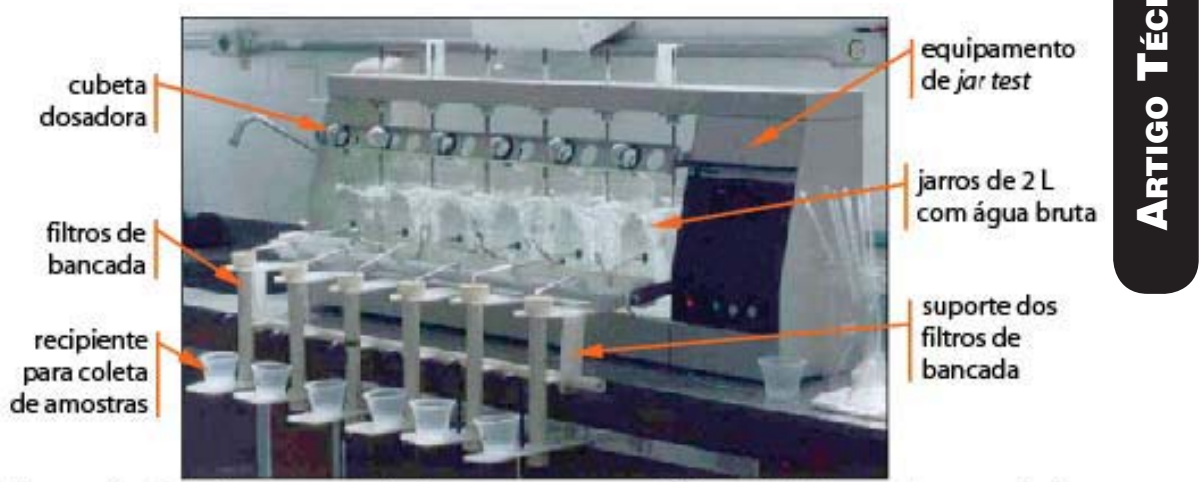

Figura I - Equipamento de jar test com os filtros de bancada acoplados

Tabela I - Características dos coagulantes avaliados nos ensaios

\begin{tabular}{cccc}
\hline Coagulante & $\begin{array}{c}\text { Teor de sólidos } \\
(\%)\end{array}$ & $\mathrm{Al}_{2} \mathrm{O}_{3}$ ou Fe (\%) & $\begin{array}{c}\text { Massa específica } \\
\left(\mathrm{kg} / \mathrm{m}^{3}\right)\end{array}$ \\
\hline $\begin{array}{c}\text { Sulfato de alumínio } \\
\text { líquido } 1\end{array}$ & 76,2 & 7,5 (mín.) & 1,36 \\
$\begin{array}{c}\text { Sulfato de alumínio } \\
\text { líquido 2* }\end{array}$ & 50,0 & 7,5 & 1,32 \\
Cloreto férrico & 56,9 & 13,8 & $1,42\left(20\right.$ a $\left.24^{\circ} \mathrm{C}\right)$ \\
Sulfato férrico & 49,1 & 8,6 & $1,42\left(20\right.$ a $\left.24^{\circ} \mathrm{C}\right)$ \\
PACl (10,4\% $\left.\mathrm{Al}_{2} \mathrm{O}_{3}\right)$ & 43,4 & 10,4 & 1,28 a $25^{\circ} \mathrm{C}$ \\
PACl (10,6\% $\left.\mathrm{Al}_{2} \mathrm{O}_{3}\right)$ & 47,0 & 10,6 & 1,29 a $25^{\circ} \mathrm{C}$ \\
PACl (18,0\% $\left.\mathrm{Al}_{2} \mathrm{O}_{3}\right)$ & 79,6 & 18,0 & 1,28 a $25^{\circ} \mathrm{C}$ \\
PACl (23,5\% $\left.\mathrm{Al}_{2} \mathrm{O}_{3}\right)$ & 65,0 & 23,5 & 1,28 a $25^{\circ} \mathrm{C}$ \\
Polímero I & 50,0 & - & 1,0 \\
(carga catiônica alta) & & - & 1,2 \\
Polímero II & 50,0 & & \\
(baixo peso molecular & & & \\
e carga catiônica alta) & & & \\
\hline
\end{tabular}

*Utilizado na estação de tratamento de água.

Obs.: dados obtidos dos fornecedores dos produtos.

ram observadas as recomendações do Standard Methods for the Examination of Water and Wastewater (AMERICAN PUBLIC HEALTH ASSOCIATION, 1998). Nos ensaios para determinação da alcalinidade empregou-se o método titulométrico.

\section{Descrição da instalação piloto}

A instalação piloto construída dentro da área da ETA constituiu-se do seguinte: bomba dosadora, recipiente para solução de coagulante; malha difusora inserida perpendicularmente à tubulação para garantir a mistura rápida; caixa de distribuição de vazão; filtro em acrílico; quadro piezométrico; caixa d'água; tubulaçôes; conexões e acessórios para o transporte da água coagulada; da água de lavagem e da água filtrada. Os diâmetros das tubulações estão indicados no esquema da instalação piloto (Figura 2) e as características do meio filtrante e da camada suporte encontram-se nas Tabelas 2 e 3, respectivamente. $\mathrm{O}$ meio filtrante e a camada suporte assentavam-se sobre uma placa de acrílico perfurada.

Durante a realização dos ensaios na instalação piloto, utilizou-se ora a água coagulada da própria ETA, bombeada para a instalação piloto, ora a água bruta coletada por uma derivação da tubulação da ETA e coagulada na instalação piloto.

O filtro da instalação piloto era de escoamento descendente e seu meio filtrante de camada simples. Como esse filtro funcionava com taxa de filtração constante e nível variável, e os filtros da ETA funcionavam com taxa declinante variável, utilizou-se a 
Tabela 2 - Características do meio

filtrante utilizado na instalação piloto

\begin{tabular}{cc}
\hline \multicolumn{2}{c}{ Meio filtrante } \\
\hline espessura & $0,5 \mathrm{~m}$ \\
$\varphi$ menor grão & $0,40 \mathrm{~mm}$ \\
$\varphi$ maior grão & $1,19 \mathrm{~mm}$ \\
coeficiente de desuniformidade & $1,6-1,7$ \\
tamanho efetivo dos grãos & $0,43 \mathrm{~mm}$ \\
\hline
\end{tabular}

Tabela 3 - Características da camada suporte utilizada na instalação piloto

\begin{tabular}{ccccc}
\hline \multicolumn{4}{c}{ Camada suporte $-40 \mathrm{~cm}$ de espessura } \\
camada & diâmetro & $(\mathrm{mm})$ & espessura $(\mathrm{cm})$ \\
\hline superior & 4,8 & - & 2,4 & 6 \\
intermediária & 12,7 & - & 4,8 & 6 \\
intermediária & 19 & - & 12,7 & 6 \\
intgermediária & 38 & - & 19 & 6 \\
inferior & 50 & - & 37 & 12 \\
\hline
\end{tabular}

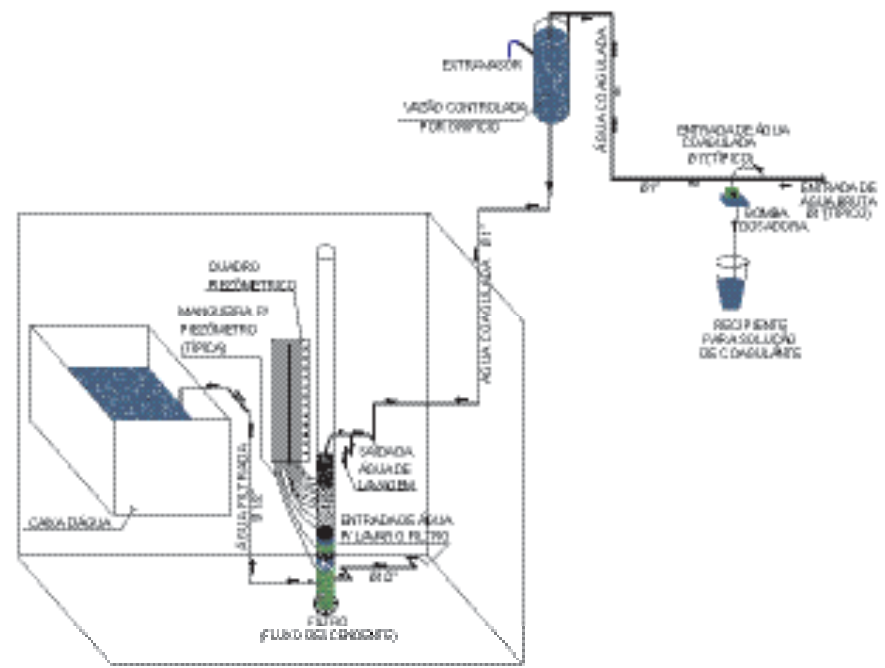

Figura 2 - Esquema da instalação piloto metodologia proposta por Di Bernardo (1993) para simular a duração da carreira de filtração que os filtros da ETA teriam se funcionassem com a taxa de filtração declinante variável e com o meio filtrante da instalação piloto. Essa metodologia descreve o comportamento de uma bateria de filtros, através de um sistema de equações, utilizando um programa de computador. Nesse programa, inserem-se os dados para as condições preestabelecidas dos filtros da ETA em escala real, ou seja: i) a taxa média de filtração; ii) o valor de carga hidráulica disponível para retenção de impurezas (neste caso, considerou-se o meio filtrante da instalação piloto); iii) o número de unidades filtrantes; e iv) as constantes e os coeficientes da equação geral da perda de carga. Após o processamento do programa, obtêmse as taxas de filtração e as variações de nível de água nos filtros, tanto durante a operação, quanto no período em que um filtro é retirado para lavagem.

Para aplicação da metodologia, o filtro da instalação piloto deve funcionar com taxa constante igual à máxima calculada. A variação da perda de carga deve ser medida no filtro piloto, por meio de piezômetros, juntamente com o tempo de funcionamento correspondente à diferença N2 - N1, também calculada pelo programa, onde N2 é o nível em que filtro deverá ser lavado e N1 é o nível mínimo do canal de distribuição de água nos filtros.

\section{Procedimento experimental}

O procedimento experimental foi composto de cinco etapas:

i) ensaios para a escolha da areia a ser utilizada nos ensaios em bancada;

ii) ensaios de jar test para elaboração dos diagramas de coagulação;

iii) realização de novos ensaios para confirmação das melhores dosagens dos coagulantes avaliados;

iv) para os melhores resultados aferidos na etapa ii, ensaios de bancada e contagem de fitoplâncton;

v) ensaios na instalação piloto para confirmação dos ensaios em bancada, realizando-se também contagem de fitoplâncton e estimativa da duração da carreira de filtração.

Primeiramente (etapa i), fez-se a escolha da areia a ser utilizada nos filtros fixados ao equipamento de jar test, utilizando a água coagulada da própria estação. Foram testadas quatro granulometrias de areia, considerando as peneiras da série de Tyler. A areia 1 ficou retida na malha 12-14; a areia 2 , na 14-16; a areia 3, na 16-20; e a areia 4, na 24-28. Cada um dos seis filtros era preenchido com a areia a ser testada. Então, a água coagulada era filtrada por $10 \mathrm{~min}$, coletando-se amostras para medir a turbidez e compará-la com a turbidez obtida do efluente da ETA. Das areias testadas, empregou- se, nos ensaios para elaboração dos diagramas de coagulação, aquela cuja granulometria mais se aproximou do efluente produzido na estação, ou seja, a areia 2.

Depois (etapa ii), os ensaios em reatores estáticos foram realizados com água bruta coletada na estação, sempre no dia anterior à realização de cada série de ensaios, sendo caracterizada em termos de $\mathrm{pH}$, alcalinidade, cor aparente e turbidez. Para cada coagulante testado, realizava-se uma série de ensaios, utilizando-se a mesma dosagem de coagulante em todos os jarros e variando-se o volume de ácido para ajuste de $\mathrm{pH}$ em cada jarro, exceto nos ensaios em que se utilizou, juntamente com o coagulante, polímero como auxiliar de coagulação. Nesses, somente a dosagem do polímero variou, mantendo-se as dosagens de ácido e de coagulante em cada ensaio.

Cada solução de coagulante era preparada no dia do respectivo ensaio, com concentração de $1 \%$ massa por volume. A concentração das soluções preparadas com polímeros era de $0,1 \%$ e o $\mathrm{pH}$ de coagulação ajustado utilizando-se ácido clorídrico a 0,1 M.

Para a mistura rápida foi adotado o gradiente de velocidade médio $\left(\mathrm{G}_{\mathrm{mr}}\right)$ de $1.000 \mathrm{~s}^{-1}$ e o tempo de mistura rápida $\left(\mathrm{T}_{\mathrm{mr}}\right)$ de $10 \mathrm{~s}$. Nos ensaios realizados com coagulantes juntamente com polímeros, foram utilizados dois procedimentos. No primeiro, adicionava-se o 
coagulante à água bruta, misturando-o $\operatorname{com} \mathrm{G}_{\mathrm{mr}}=1.000 \mathrm{~s}^{-1} \mathrm{e}_{\mathrm{mr}}=10 \mathrm{~s} \mathrm{e}$, imediatamente após a mistura rápida, adicionava-se o polímero e diminuía-se o gradiente de velocidade para $800 \mathrm{~s}^{-1}$, mantendo a mistura rápida por mais 25 segundos. No segundo, misturava-se o coagulante e o auxiliar à água bruta simultaneamente, com gradiente de velocidade médio de $1.000 \mathrm{~s}^{-1} \mathrm{e}$ tempo de mistura de $10 \mathrm{~s}$. Em todos os ensaios, após a mistura rápida, o gradiente de velocidade médio era reduzido para $90 \mathrm{~s}^{-1}$ - para evitar a deposição de sólidos no fundo dos jarros - a água era filtrada por dez minutos antes de se fazer a coleta das amostras. Ao término de cada ensaio, os jarros e as cubetas dosadoras eram limpos, a areia retirada dos filtros de bancada, lavada e recolocada nos filtros para a realização de outra série de ensaios, obedecendo à mesma seqüência. A Tabela 4 apresenta o quadro sinóptico dos ensaios em jar test para elaboração dos diagramas de coagulação (etapa ii).

Nestes ensaios preliminares de bancada, procurou-se identificar o melhor par, dosagem de coagulante e $\mathrm{pH}$ de coagulação, adequado à tecnologia de filtração direta, de forma que a turbidez e a cor aparente remanescentes atendessem às recomendações da Portaria 518/2004 do Ministério da Saúde.

Posteriormente (etapa iii), foram realizados novos ensaios de bancada, com o propósito de confirmar as dosagens de coagulantes e o $\mathrm{pH}$ de coagulação dos ensaios da fase anterior, repetindo algumas dosagens utilizadas $\mathrm{e}$ excluindo outras de antemão. Procurouse selecionar as dosagens de coagulante e pH de coagulação que forneceram os menores valores de turbidez e de cor aparente remanescentes. Também foram testados mais dois tipos de $\mathrm{PACl}$, com teores de alumina diferentes dos anteriores, optando-se por não fazer ajuste do $\mathrm{pH}$ de coagulação diante dos resultados obtidos.

A partir da dosagem de coagulante e o pH de coagulação definido foram coletadas amostras para contagem do fitoplâncton (etapa iv), visando avaliar a eficiência do coagulante testado na redução do fitoplâncton. Para cada coagulante foram realizados três ensaios de jar test e em todos se coletaram amostras para contagem de fitoplâncton.

Por fim, foram realizados ensaios em escala piloto (etapa v). Para tal, após lavagem do filtro piloto por pelo menos 5 minutos, abria-se o registro de entrada de água coagulada afluente, deixando funcionar por aproximadamente sete minutos, até que se atingisse equilíbrio entre a vazão de entrada e vazão de saída, de maneira a determinar o nível N1 (nível d'água decorrente da perda de carga inicial no meio filtrante). Durante os ensaios, coletavam-se amostras de água filtrada para determinação da cor aparente e turbidez remanescentes e $\mathrm{pH}$, efetuando-se as leituras nos piezômetros. $\mathrm{O}$ ensaio encerrava-se quando se atingia o nível N2 (nível d'água imediatamente anterior à lavagem), determinando-se o tempo final de funcionamento e, novamente, procedendose a leituras nos piezômetros.

Após cada carreira de filtração o filtro era lavado por cinco minutos, de modo que o leito filtrante apresentasse uma expansão de aproximadamente $30 \%$.
Para o cálculo estimado da duração da carreira de filtração dos filtros da estação considerou-se o intervalo de tempo $(\Delta \mathrm{t})$, correspondente à variação de nível (N2 - N1), multiplicando $\Delta t$ pelo número de filtros da bateria da estação de tratamento de água em escala real, neste caso 8 filtros.

\section{RESULTADOS E DISCUSSÃO}

\section{Características da água bruta}

De acordo com o monitoramento realizado pela concessionária, a água bruta apresentou, no período de 2000 a 2003, turbidez sempre inferior a $7 \mathrm{uT}$, com $87,4 \%$ das observaçóes menores que 4,5 uT. Para os valores de cor aparente, $83,4 \%$ das observaçôes estiveram entre 10 e $20 \mathrm{uH}$ e $98,1 \%$ inferiores a $35 \mathrm{uH}$.

Durante a realização dos ensaios, no período de março a julho de 2003 e de fevereiro a agosto de 2004, salvo a ocorrência de dois picos de pequena expressão de cor aparente e turbidez (da ordem de 55 uH e 9 uT), a água bruta apresentou resultados de mesma magnitude, com 90,8\% dos valores de turbidez abaixo de 4 uT e $72,8 \%$ dos valores de cor aparente inferiores a $35 \mathrm{uH}$.

$\mathrm{O} \mathrm{pH}$, por sua vez, atingiu um valor mínimo de 7,2 em maio de 2001 e em maio de 2003. Já o valor máximo de 8,7 ocorreu em abril de 2002. Durante os ensaios, o $\mathrm{pH}$ da água bruta foi de $7,6 \pm 0,2$ e a alcalinidade $53 \pm 3 \mathrm{mg} / \mathrm{L}$ $\mathrm{CaCO}_{3}$.

Tabela 4 - Quadro sinóptico dos ensaios em jar test

\begin{tabular}{|c|c|c|c|c|c|c|c|c|c|c|c|c|c|}
\hline \multirow{2}{*}{$\begin{array}{c}\text { Coagulante } \\
\text { Sulfato de alumínio } 1\end{array}$} & \multirow{2}{*}{$\begin{array}{c}\text { Polímero } \\
-\end{array}$} & \multicolumn{6}{|c|}{$\begin{array}{c}\text { Dosagens de coagulante } \\
(\mathrm{mg} / \mathrm{L})\end{array}$} & \multicolumn{5}{|c|}{$\begin{array}{c}\text { Dosagens de polímero } \\
(\mathrm{mg} / \mathrm{L})\end{array}$} & \multirow{2}{*}{$\begin{array}{c}\begin{array}{c}\text { No de } \\
\text { ensaios }\end{array} \\
5\end{array}$} \\
\hline & & 3 & 6 & 9 & 11,5 & 15 & & & & - & & & \\
\hline Cloreto férrico & - & 1,2 & 2,4 & 3,6 & 4,8 & 6 & 7,2 & & & - & & & 6 \\
\hline Cloreto férrico & - & 1,2 & 2,4 & 3,6 & 4,8 & 6 & 7,2 & & & - & & & 6 \\
\hline Sulfato de alumínio 2 & - & 3,3 & 6,7 & 10 & 13,4 & 16,8 & 20 & & & - & & & 6 \\
\hline Sulfato férrico & - & 2,8 & 5,5 & 8,3 & 11,1 & 13,9 & 16,6 & & & - & & & 6 \\
\hline $\mathrm{PACl} 10,6 \% \mathrm{Al}_{2} \mathrm{O}_{3}$ & - & 1 & 2,1 & 3,1 & 4,2 & 5,2 & & & & - & & & 5 \\
\hline Sulfato de alumínio 2 & LT 31 & 6 & & & & & & 0,1 & 0,25 & 0,5 & 0,75 & 1 & 4 \\
\hline Sulfato de alumínio 2 & LT 7981 & 6 & & & & & & 0,1 & 0,25 & 0,5 & 0,75 & 1 & 5 \\
\hline Sulfato férrico & LT 31 & 6 & & & & & & 0,1 & 0,25 & 0,5 & 0,75 & 1 & 6 \\
\hline $\mathrm{PACl} 10,4 \% \mathrm{Al}_{2} \mathrm{O}_{3}$ & - & 3 & 6 & 7,5 & 9 & 10 & 12 & & & - & & & 6 \\
\hline
\end{tabular}

Obs.: Para todos os ensaios caracterizou-se a água bruta. 
Em relação ao número de organismos do fitoplâncton, os dados operacionais da estação apontaram redução no período de 2001 a 2003. Durante os experimentos o número de organismos nas amostras de água bruta foi relativamente baixo, tendo variado de 2 a 4.029 organismos $/ \mathrm{mL}$. Tais resultados confirmaram a melhoria hidrobiológica da água bruta, conseqüência da redução do aporte de esgotos ao reservatório.

\section{Diagramas de coagulação}

Conforme mencionado, foram elaborados diagramas de coagulação para Sulfato de Alumínio, Cloreto Férrico, Sulfato Férrico, Hidróxi-Cloreto de Alumínio, Sulfato de Alumínio com polímero e Sulfato Férrico com polímero. Exemplo de um dos diagramas (no caso, Cloreto Férrico) está apresentado na Figura 3, na qual os números superiores referem-se à turbidez e os inferiores à cor aparente, ambas remanescentes, com destaque para as eficiências obtidas sem adição de ácido. Observa-se que, com dosagens de $6 \mathrm{mg} / \mathrm{L}$ e pH 6,6, foram obtidos valores de turbidez e cor aparente de 0,57 uT e $9 \mathrm{uH}$, respectivamente, atendendo a Portaria 518/2004.

$\mathrm{Na}$ Figura 4 são apresentados os melhores resultados extraídos dos respectivos diagramas de coagulação para os dois tipos sulfato de alumínio testados, comprados de fornecedores distintos. $\mathrm{Na}$ avaliação dos dois tipos de Sulfato de Alumínio, os resultados apontaram eficiência de mesma magnitude, à exceção de uma melhor remoção da cor aparente para a dosagem de $15 \mathrm{mg} / \mathrm{L}$ de um dos sais, no caso o Sulfato de Alumínio 1.

Posteriormente, foram testados polímeros em conjunto com o Sulfato de Alumínio 2, por ser o coagulante em uso na estação. Com a dosagem do sal fixada em $6 \mathrm{mg} / \mathrm{L}$, efetuava-se a correção de $\mathrm{pH}$ e variavam-se as dosagens de polímero. Ora o polímero era adicionado ao jarro após a mistura rápida do coagulante com a água bruta, ora o polímero e o coagulante eram misturados simultaneamente. Não foram observadas diferenças significativas entre os dois procedimentos, confirmando o aumento da eficiência da coagulação com dosagem de polímero da ordem de 0,25 a $0,50 \mathrm{mg} / \mathrm{L}$ e a possibilidade da aplicação de um auxiliar de coagulação em escala real.

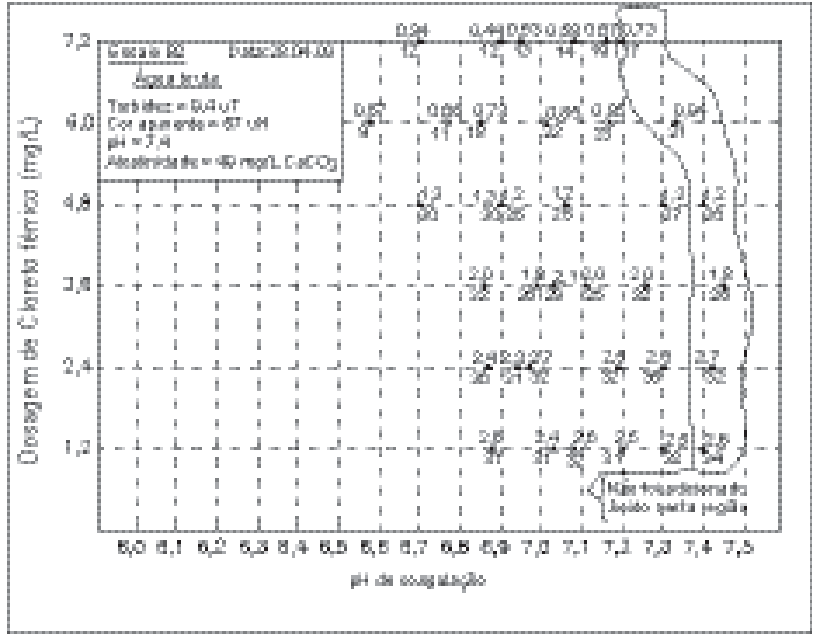

Figura 3 - Diagrama de coagulação para Cloreto Férrico

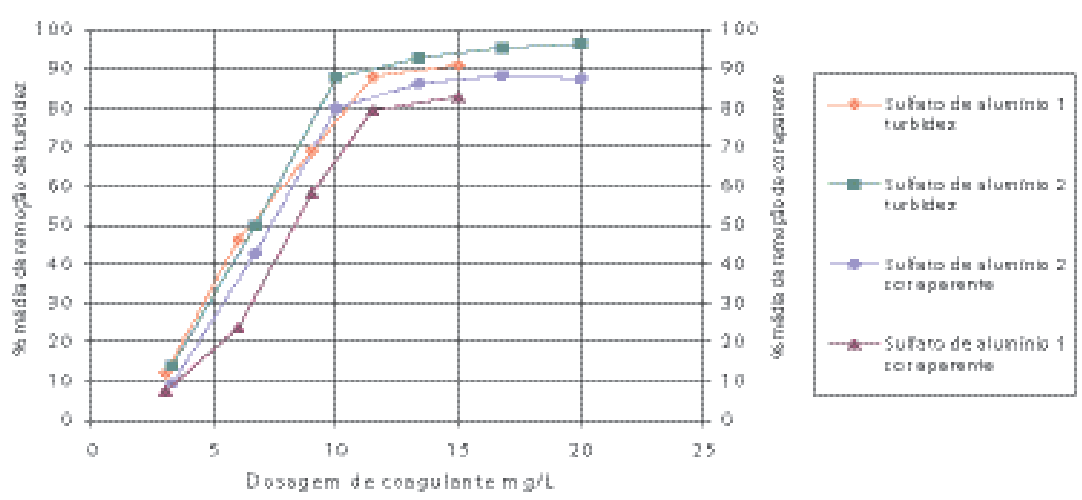

Figura 4 - Comparação entre diferentes tipos de Sulfato de Alumínio

Diante dos resultados obtidos nessa análise, concluiu-se que todos os coagulantes avaliados seriam, a princípio, recomendados para a tecnologia de filtração direta. Para seleção de uma única dosagem para cada coagulante, realizaram-se novos ensaios em jar test utilizando as melhores dosagens e o $\mathrm{pH}$ de coagulação selecionados nessa etapa como referência.

\section{Comparação entre os coagulantes}

Nesta etapa, realizaram-se comparações utilizando os valores médios dos parâmetros analisados obtidos das réplicas dos ensaios executados. Para os distintos tipos de $\mathrm{PACl}$ são apresentadas comparaçôes em milimoles por litro $(\mathrm{mM} / \mathrm{L})$ de metal coagulante. Ainda que normalizadas em termos de milimoles de metal coagulante, as mesmas dosagens de coagulante podem variar, dependendo do fabricante do produto, conforme já mencionado.
$\mathrm{Na}$ Figura 5 apresentam-se comparações entre dosagens e cor aparente remanescente. Observa-se melhor desempenho do $\mathrm{PACl}$ 10,6\% $\mathrm{Al} 2 \mathrm{O} 3$ na redução de cor aparente com menores dosagens de $\mathrm{Al}$.

Embora o PACl 10,6\% Al2O3 tenha reduzido a cor aparente e a turbidez com menores quantidades de metal coagulante, não há como afirmar que a quantidade de lodo gerado em função da quantidade de metal contido no coagulante também seja menor, sem a realização de ensaios específicos, pois a quantidade de metal contida no coagulante é menor. No entanto, a dosagem utilizada de coagulante, em $\mathrm{mg} / \mathrm{L}$, é a mesma. Por outro lado, quando se faz o tratamento da água utilizando um coagulante que contém menor quantidade de metal, a possibilidade de se obter metal residual é menor.

Com os resultados obtidos nesta etapa, definiram-se as seguintes dosagens para cada coagulante: a) para os distintos $\mathrm{PACl}: 5 \mathrm{mg} / \mathrm{L}$; b) para o 
Sulfato de Alumínio, o Cloreto Férrico e o Sulfato Férrico isoladamente, 6 e $8 \mathrm{mg} / \mathrm{L}$; c) para o Sulfato de Alumínio, o Cloreto Férrico e o Sulfato Férrico com polímeros, $6 \mathrm{mg} / \mathrm{L}$ de coagulante e $0,5 \mathrm{mg} / \mathrm{L}$ de polímero. Essas dosagens foram escolhidas com o propósito de se realizar uma análise final dos ensaios de bancada quanto à redução de cor aparente e turbidez, bem como avaliar a contagem de fitoplâncton.

\section{Análise final dos ensaios de bancada e contagem do fitoplâncton}

Ensaios de bancada

Para análise final dos resultados dos ensaios de bancada, foram utilizados os valores médios de turbidez e de cor aparente remanescentes para as dosagens mencionadas, os mesmos utilizados para análise de variância.

Conforme as Figuras 6 e 7 evidenciam, todos os coagulantes atenderam às recomendações da já mencionada Portaria 518/2004, quanto aos valores de cor aparente e de turbidez remanescentes que são de $15 \mathrm{UH}$ e 1,0 uT respectivamente. Com relação aos resultados de percentuais de remoção de cor aparente e de turbidez, ocorreram diferenças entre coagulantes.

Para verificar se essas diferenças foram significativas quanto a esses percentuais, utilizou-se a análise de variância, cuja síntese é apresentada na Tabela 5.

As análises de variâncias mostraram que não houve diferenças significativas, quanto à remoção de turbidez e de cor aparente, entre os coagulantes utilizados.

\section{Contagem do fitoplâncton}

$\mathrm{Na}$ contagem do fitoplâncton, procurou-se classificar as algas em classe e gênero. Nas análises das amostras de água bruta foram identificadas as seguintes classes principais: Bacillariophyceae, Chlorophyceae Cyanophyceae, Dinophyceae, Euglenophceae e Zygnemaphycea. Entre as algas encontradas, a maioria pertencia à classe Chlorophyceae, e em sua quase totalidade podem conferir sabor e odor à água, além de contribuírem para a colmatação dos filtros. Da classe Cyanophceae foram encontrados os gêneros Microcystis sp., Lyngbya sp. e Merismopedia sp.

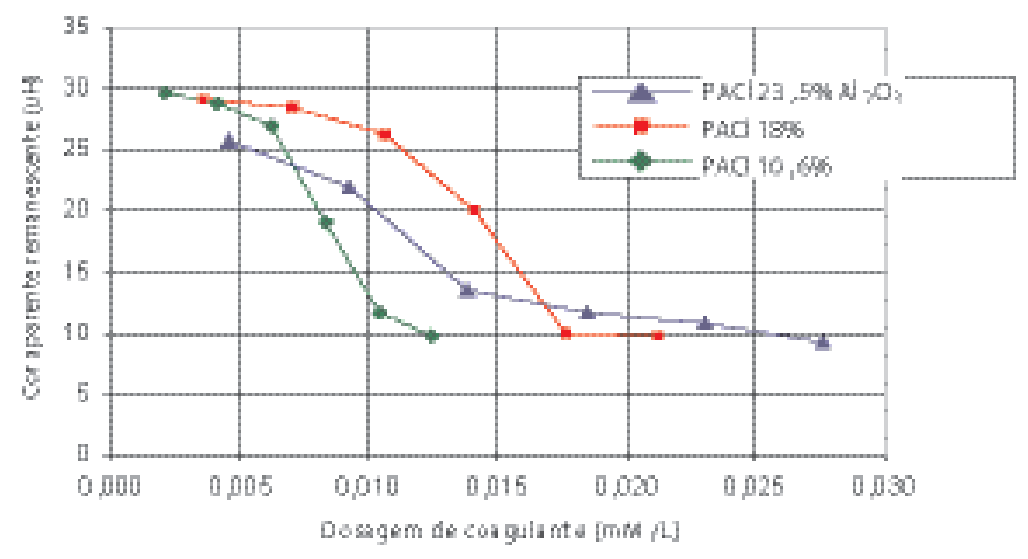

Figura 5 - Comparação entre distintos PACI em termos de remoção da cor aparente

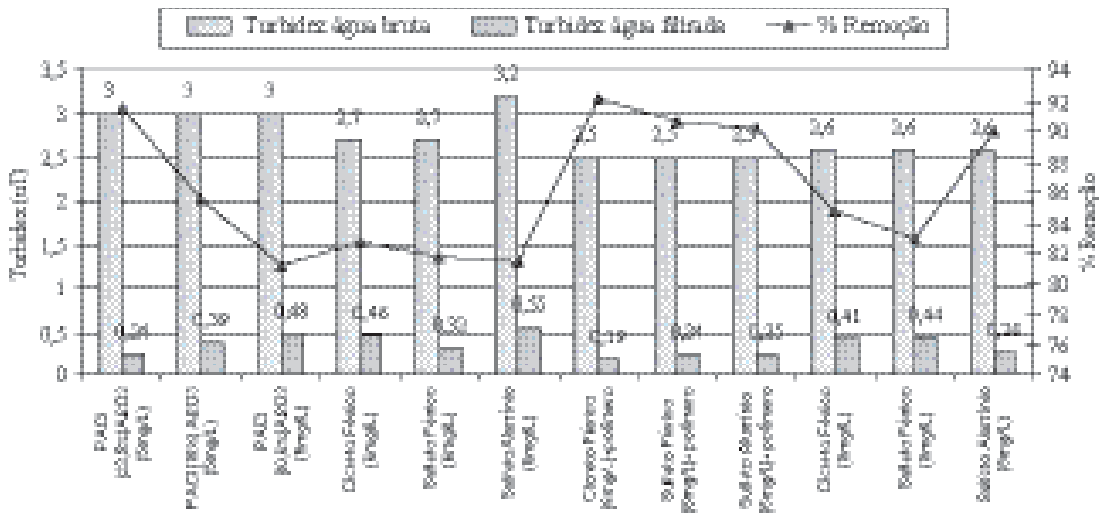

Figura 6 - Percentagem de remoção e turbidez

Tabela 5 - Resumo dos resultados da análise de variância para os ensaios de laboratório

\begin{tabular}{cccc}
\hline $\begin{array}{c}\text { Item } \\
\text { analisado }\end{array}$ & $\begin{array}{c}\text { Probabilidade } \\
(p) \text { encontrada }\end{array}$ & $p_{0=0,05}$ & $\begin{array}{c}\text { Hipótese } \\
\mathrm{H}_{0}\end{array}$ \\
\hline \% de remoção de turbidez & $p=0,393$ & $p>p_{0}$ & aceito $\mathrm{H}_{0}$ \\
\% de remoção de cor aparente & $p=0,06$ & $p>p_{0}$ & aceito $\mathrm{H}_{0}$ \\
\hline
\end{tabular}

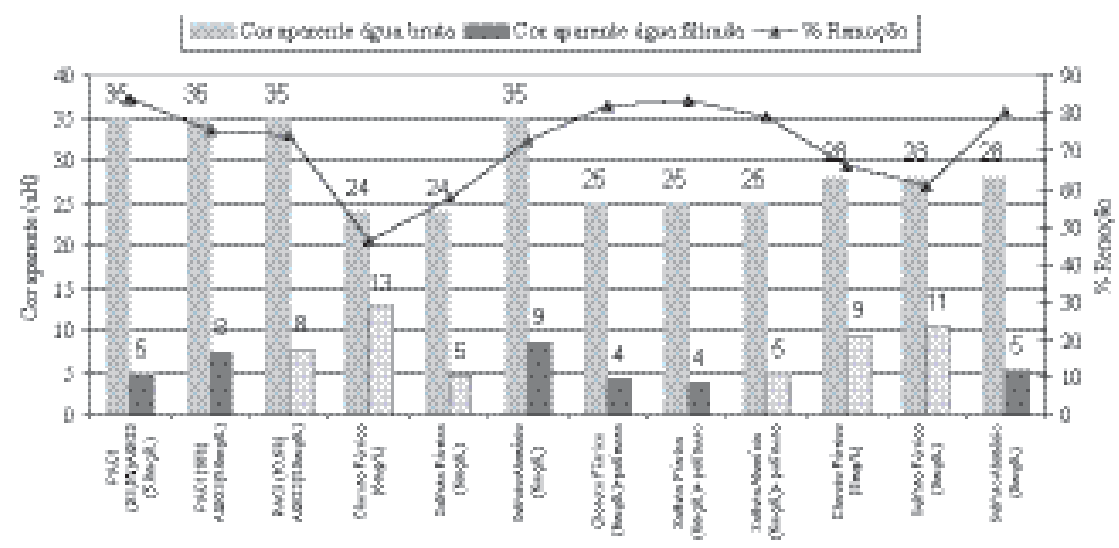

Figura 7 - Percentagem de remoção e cor aparente remanescente para os coagulantes avliados 
Em algumas amostras de água filtrada foram identificadas espécies de algas não detectadas na água bruta, fato desconsiderado para a realização do cálculo de remoção de organismos $/ \mathrm{mL}$. Espécies não encontradas na água bruta podem ter sido encontradas na água filtrada em razão de as amostras terem sido coletadas em momentos diferentes ou porque a contagem de organismos ser realizada estatisticamente, devido à impossibilidade de contar todos os organismos presentes na amostra.

$\mathrm{Na}$ Figura 8 são apresentados os resultados de um dos ensaios de remoção de organismos, de turbidez e cor aparente. Nesses ensaios foram utilizados os seguintes coagulantes: $\mathrm{PACl}$ $23,5 \% \mathrm{Al}_{2} \mathrm{O}_{3}, \mathrm{PACl} 18 \% \mathrm{Al}_{2} \mathrm{O}_{3}, \mathrm{PACl}$ $10,6 \% \mathrm{Al}_{2} \mathrm{O}_{3}$, Cloreto Férrico, Sulfato Férrico e Sulfato de Alumínio 2, os três últimos tanto isoladamente quanto com polímeros.

Observa-se na Figura 8 que a curva de percentual de remoção de organismos, nos pontos em que se utilizou o Sulfato Férrico e o Sulfato de Alumínio 2 , com dosagens de $8 \mathrm{mg} / \mathrm{L}$, não acompanhou as curvas de remoção de cor aparente e de turbidez. Para a água filtrada, quando se utilizou o Sulfato de Alumínio 2 como coagulante, a remoção de cor aparente e a de turbidez ficaram acima de $80 \%$, enquanto a remoção de organismos ficou próxima dos 70\%. Todas as amostras de água filtrada tiveram o percentual de remoção de organismos acima de $90 \%$, exceto nas amostras em que foram utilizados o $\mathrm{PACl} 18 \% \mathrm{Al}_{2} \mathrm{O}_{3}$, o PACl 10,6\% $\mathrm{Al}_{2} \mathrm{O}_{3}$ (ambos com dosagem de $5 \mathrm{mg} / \mathrm{L}$ ) e o Sulfato de Alumínio 2 (com dosagem de $8 \mathrm{mg} / \mathrm{L}$ ), que tiveram os percentuais de remoção de $74 \%, 67 \%$ e $70,5 \%$ respectivamente.

Posteriormente, foram realizadas réplicas utilizando $\mathrm{PACl} 18 \% \mathrm{Al}_{2} \mathrm{O}_{3}$, $\mathrm{PACl} 23,5 \% \mathrm{Al}_{2} \mathrm{O}_{3}, \mathrm{PACl} 10,6 \% \mathrm{Al}_{2}^{2} \mathrm{O}_{3}$ com dosagem de $5 \mathrm{mg} / \mathrm{L}$, e Sulfato de Alumínio, com $6 \mathrm{mg} / \mathrm{L}$. Os melhores resultados sucederam-se com o $\mathrm{PACl}$ 23,5\% (5,0 mg/L) para os dois ensaios, obtendo-se remoção de $94 \%$ e $97 \%$ de fitoplâncton, $90 \%$ e $95 \%$ de turbidez e $90 \%$ e $90 \%$ de cor aparente. O percentual mais baixo de remoção de fitoplâncton ocorreu na primeira amostra de água filtrada na qual se utilizou o Sulfato de Alumínio, obtendo-se apenas $56 \%$, enquanto os percentuais de remoção de cor aparente e de turbidez foram superiores a $80 \%$, mostrando que alcançar um percentual de remoção de turbidez elevado não assegura remoção de organismos na mesma proporção. Esta constatação confirma pesquisa anterior, na qual concluiu-se que mesmo para valores de turbidez menores que 0,5 uT, a qualidade microbiológica, no que tange ao fitoplâncton, pode não ser assegurada (Ferreira et al, 2003).

\section{Ensaios em escala piloto}

Para a execução dos ensaios em escala piloto, utilizou-se a taxa máxima de filtração $\left(436 \mathrm{~m}^{3} \cdot \mathrm{m}^{-2} \cdot \mathrm{d}^{-1}\right)$ e a carga hidráulica para retenção de impurezas de $15 \mathrm{~cm}$, obtida pela diferença de nível (N2 - N1), conforme metodologia.

Para tornar a comparação mais acurada, foram inicialmente realizados ensaios na unidade piloto utilizando-se a água coagulada da estação de tratamento em escala real. As dosagens de coagulante utilizadas nestes ensaios foram 8,1 mg/L; 9,0 mg/L e 8,2 mg/L. Nesta etapa todos ensaios encerravamse quando a carga hidráulica atingia $15 \mathrm{~cm}$, o que corresponde à variação de nível (N2-N1). Os resultados, em termos de cor aparente, estão apresentados na Figura 9.

Observa-se na Figura 9 que o ensaio que teve a duração de carreira de filtração mais longa foi o primeiro $(3,63 \mathrm{~h})$ e a mais curta o terceiro $(2,92 \mathrm{~h})$. Todas as amostras apresentaram valores de cor aparente remanescente menores que $15 \mathrm{uH}$, atendendo às recomendações da Portaria 518/2004, exceto para o primeiro ensaio quando a cor aparente atingiu $16 \mathrm{uH}$. Para turbidez, o percentual médio de remoção foi da ordem de $69 \%$, com apenas uma única amostra com turbidez inferior a 0,5 uT. A duração média da carreira de filtração desses ensaios atingiu $3,24 \mathrm{~h}$, permitindo estimar em $25 \mathrm{~h}$ (8 filtros $\times 3,24 \mathrm{~h}$ ) para escala real, duração superior aos valores médios registrados na estação (9 a 14h).

Posteriormente, realizaram-se três ensaios, fazendo-se a coagulação na própria instalação piloto ao invés de se utilizar a água coagulada na ETA em escala real como nos anteriores. $\mathrm{O}$ coagulante utilizado para esses ensaios foi o Sulfato de Alumínio 2 (8,0 mg/L) e ácido para corrigir o $\mathrm{pH}$ de coagulação. A qualidade da água filtrada nesses ensaios foi superior àquela do ensaio em que se utilizou a água coagulada da ETA em escala real.

Todas as amostras apresentaram cor aparente inferior a $10 \mathrm{uH}$ e turbidez inferior a 0,50 uT. Contudo, a duração média da carreira de filtração foi de 33,7 min, apontando para apenas 4,5 h (8 filtros $\times 33,7 \mathrm{~min}$.) em escala real. A duração da carreira de filtração nesses ensaios foi mais curta em relação às anteriores, provavelmente pelas seguintes razões: i) maior retenção de partículas no leito filtrante, uma vez que os resultados de turbidez obtidos após a filtração foram mais baixos; e ii) não realização de pré-cloração, praticada na estação em escala real.

Da mesma forma, quando de empregou o $\mathrm{PACl} 10.6 \% \mathrm{Al}_{2} \mathrm{O}_{3}(5,0 \mathrm{mg} / \mathrm{L})$ todas as amostras apresentaram cor aparente inferior a $10 \mathrm{uH}$ e turbidez remanescente abaixo de $0,50 \mathrm{uT}$. Novamente a duração média da carreira de filtração foi de mesma magnitude,

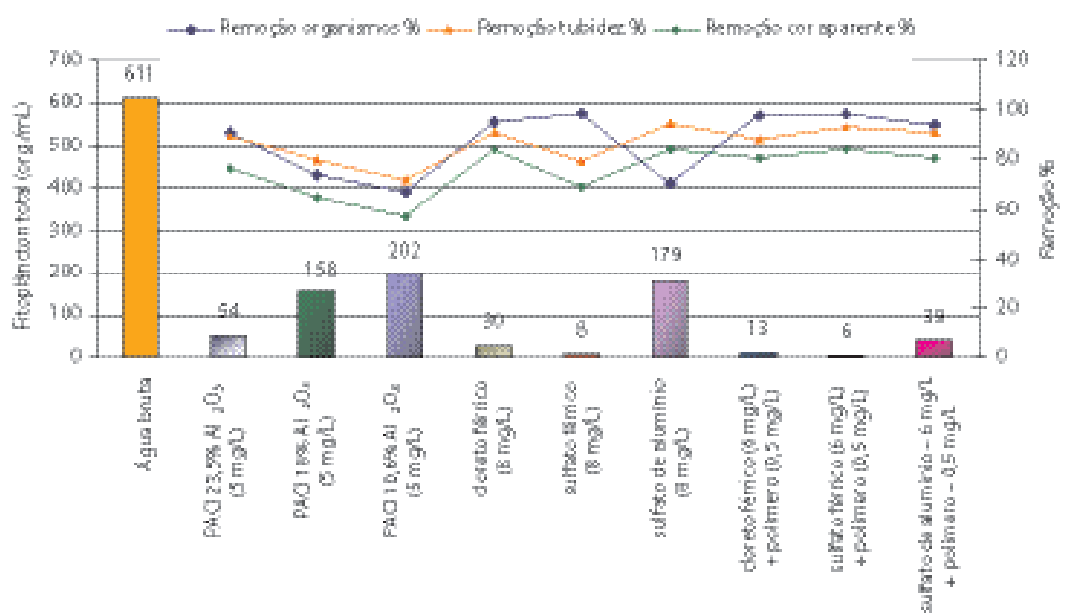

Figura 8 - Fitoplâncton e percentual de remoção para as amostras dos ensaios de laboratório 
$37 \mathrm{~min}$; o que permite estimar a carreira de filtração em 5 h ( 8 filtros $\times 37 \mathrm{~min})$ em escala real.

Os percentuais de remoção de turbidez, quando se utilizou o Sulfato de Alumínio 2 com dosagem de 8,0 mg/L e com correção do $\mathrm{pH}$ de coagulação, foram superiores aos percentuais de remoção dos demais coagulantes. Para os resultados de remoção de cor aparente, o PACl $10,6 \% \mathrm{Al}_{2} \mathrm{O}_{3}$ e o Sulfato de Alumínio 2 apresentaram percentuais de remoção superiores aos de quando se utilizou a água coagulada da estação em escala real.

Para comparar os resultados dos ensaios em escala de bancada com os ensaios em escala piloto, utilizou-se um teste não paramétrico, no caso, teste $U$ de Mann-Whitney, considerando um nível de significância de 5\%. Os resultados mostraram que, para o $\mathrm{PACl} 10,6 \%$ $\mathrm{Al}_{2} \mathrm{O}_{3}$ e para o Sulfato de Alumínio 2 junto com ácido, não houve diferença significativa quanto à remoção de cor aparente e de turbidez. Para os valores de $\mathrm{pH}$, quando se utilizou o Sulfato de Alumínio 2 junto com ácido, também não houve diferença significativa. Já para o $\mathrm{PACl} 10,6 \% \mathrm{Al}_{2} \mathrm{O}_{3}$, os valores de $\mathrm{pH}$ obtidos nos ensaios de laboratório foram superiores aos obtidos na instalação piloto.

Os resultados de remoção de fitoplâncton para um dos ensaios realizados na instalação piloto são apresentados na Figura 10. Como ocorreu nas amostras dos ensaios de bancada para contagem de fitoplâncton, também nesses ensaios foram encontradas espécies que não tinham sido encontradas nas amostras de água bruta.

Observa-se que uma maior remoção de organismos (98\%) se deu no primeiro ensaio, quando se utilizou Sulfato de Alumínio 2 e ácido. Notase ainda que o percentual de remoção de organismos reduziu-se, ainda que pouco, de ensaio para ensaio. Isso pode ter ocorrido por alteração na qualidade da água bruta ou em função de alguma imprecisão na contagem de fitoplâncton, conforme mencionado anteriormente.

\section{CONCLUSÕES E RECOMENDAÇỐES}

Os resultados obtidos nos ensaios em bancada permitem concluir que todos os coagulantes testados podem ser utilizados para tecnologia de filtração

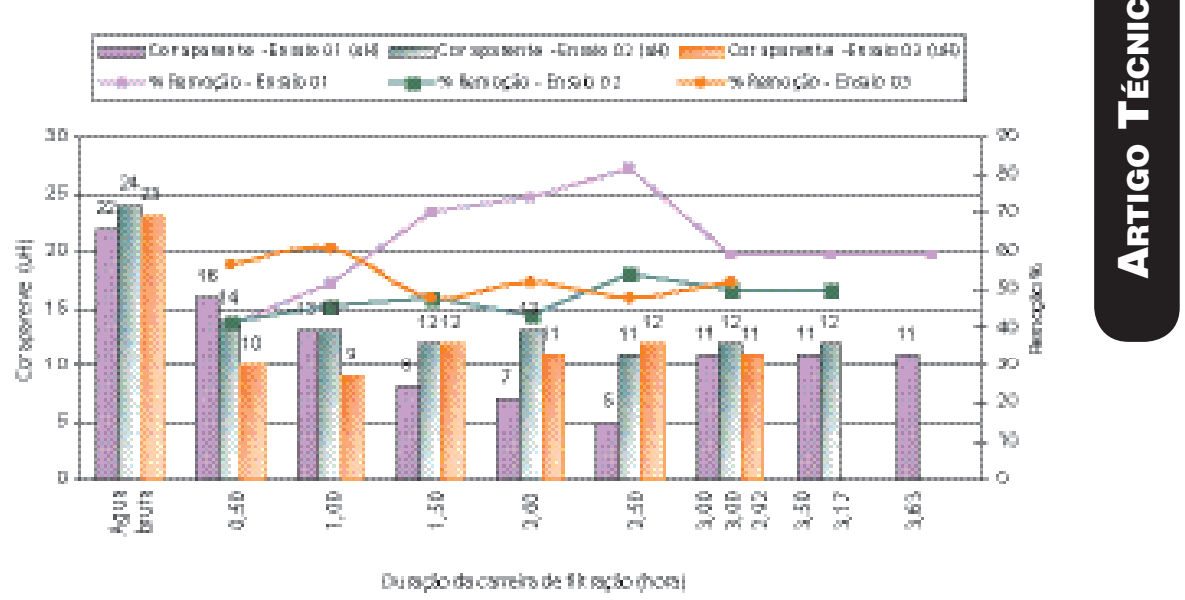

Figura 9 - Resultados dos ensaios na unidade piloto
utilizando a água coagulada da ETA

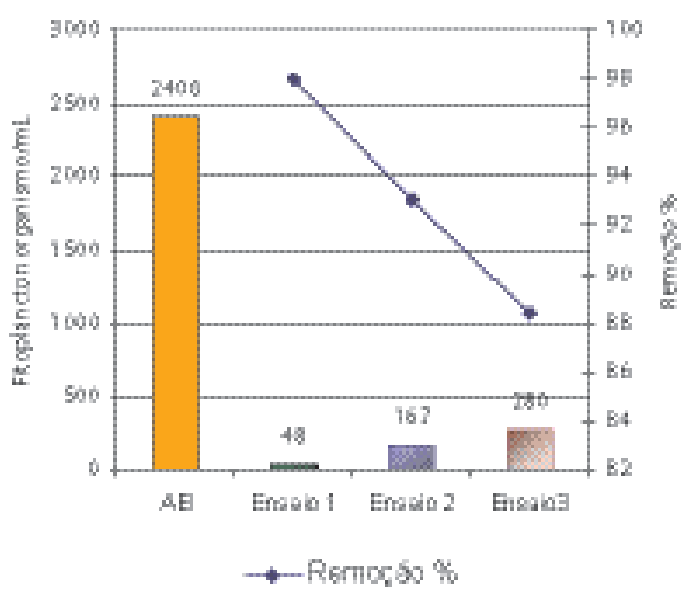

Figura 10 - Fitoplâncton e porcentagem de remoção na instalação piloto utilizando Sulfato de Alumínio 2 e ácido

direta em linha. Não houve diferença significativa, considerando nível de significância de 5\%, dos percentuais de remoção de cor aparente e de turbidez para os ensaios de bancada, quando foram utilizados os coagulantes Cloreto Férrico, Sulfato de Alumínio, Sulfato Férrico e Hidróxi-Cloreto de Alumínio, isoladamente ou combinados com polímeros catiônicos.

Dentre os três coagulantes analisados no filtro piloto, o que apresentou melhores resultados quanto aos parâmetros de cor aparente e de turbidez remanescentes foi o Sulfato de Alumínio 2 juntamente com ácido. As carreiras de filtração foram mais longas quando se utilizou a água coagulada da ETA em escala real, onde se usa o Sulfato de Alumínio 2 juntamente com o cloro para fazer a pré-cloração. A carreira de filtração obtida por meio da simulação foi de 25 horas, duração maior do que a atualmente observada na estação. A pré-cloração provavelmente contribuiu para que as carreiras de filtração fossem mais longas. No entanto a qualidade da água filtrada foi inferior à dos outros dois coagulantes testados em escala piloto, o que não era esperado, pois a pré-oxidação também contribui para a melhora da qualidade da água filtrada. Isto pode ter ocorrido devido ao fato de a coagulação na ETA em escala real não estar sendo realizada de forma adequada ou meio filtrante utilizado na instalação piloto não ser adequado.

Os resultados obtidos de remoção de turbidez e de cor aparente, quando se utilizou o $\mathrm{PACl} 10,6 \% \mathrm{Al}_{2} \mathrm{O}_{3}$ ou o Sulfato de Alumínio 2 com ácido, não apresentaram diferenças significativas entre os ensaios de bancada e em escala piloto. 
Por fim, os resultados dos ensaios em escala piloto, nos quais o Sulfato de Alumínio 2, juntamente com ácido, apresentou excelente desempenho quanto à redução de cor aparente e turbidez, demonstrando a possibilidade do emprego de ácido na coagulação em escala real. Esta alternativa, raramente empregada no País, seria indicada para o tratamento por filtração direta de águas naturais de $\mathrm{pH}$ e alcalinidade mais elevados que empregue o mecanismo de coagulação (adsorção/neutralização de cargas). $\mathrm{Na}$ estação de tratamento em questão, o emprego do ácido pode ser testado sem a realização da pré-desinfecção que - caso haja novas floraçōes de cianobactérias ou de alguns outros gêneros de algas - pode favorecer o aporte de toxinas e substâncias passíveis de conferir odor e sabor à água tratada e de favorecer a formação de subprodutos indesejados da desinfecção.

\section{AGRADECIMENTOS}

Os autores agradecem à Fundação de Amparo à Pesquisa do Estado de Minas Gerais (Fapemig) pelo financiamento e concessão da bolsa de Iniciação Científica (Proc. TEC 116/2001), à Capes pela concessão da bolsa de mestrado e ao CNPq pela concessão das bolsas Profix e Produtividade em Pesquisa.

\section{REFERÊNCIAS}

AMERICAN PUBLIC HEALTHASSOCIATION. Standard Methods for the Examination of Water and Wastewater. 20th edition. Washington, DC: American Public Health Association, 1998.

BUDD, G. C., et al. Coagulation applications for new treatment goals. Journal of American Water Works Association, 96:2, p. 102-113, Feb. 2004

DEWOLF, J., et al. Guidance Manual for Coagulant Changeover. Denver: AWWA Research Foundation and American Waterworks Association, 185 p. 2003.

DI BERNARDO, L. Métodos e Técnicas de Tratamento de Água. Rio de Janeiro: ABES - Associação Brasileira de Engenharia Sanitária e Ambiental, 1993. 498 p. Vol. 2.

DI BERNARDO, L. (Coord.) et al. Tratamento de Água para Abastecimento por Filtração Direta, Rio de Janeiro: ABES, RiMa, pp. 480. 2003.

FERREIRA, A. C. S, MOTA FILHO, C.R., PÁDUA, V. L. Relação entre turbidez e contagem do fitoplâncton na avaliação da qualidade da água para consumo. In: $22^{\circ} \mathrm{CONGRESSO}$ BRASILEIRO DE ENGENHARIA SANITÁRIA E AMBIENTAL, Joinville. ABES, 1 CD-ROM. 2003.

KAWAMURA, S. Design of basic treatment process units. In: Integrated design of water treatment facilities. Canadá: John Wiley e Sons, Inc., p. 48-309. 1991.

MINISTÉRIO DA SAÚDE. Portaria no 518, de 25 de março de 2004. Estabelece os procedimentos e responsabilidades relativos ao controle e vigilancia da qualidade da água para consumo humano $e$ seu padrão de potabilidade, e dá outras providências. Diário Oficial da União no 59 , Seção 1 , pág. 266 -70. de 26 mar. 2004.
NDIONGUE, S. DESJARDINS, R., PRÉVOST, M. The use of jar-filtration tests to compare performances of coagulants in direct filtration. Environmental Technology, Vol. 21, pp 67-76, 2000

WAGNER, E. G., HUDSON JR., H. E. Low-dosage high-rate direct filtration. Journal of American Water Works Association, p. 256. May 1982,

Endereço para correspondência:

Eliane Prado Cunha Costa dos

Santos

Rua Juvenal dos Santos 222/404

Bairro Luxemburgo

30380-530 - Belo Horizonte - MG

Brasil

Tel: (3I) 3297-5406

E-mail: lilial2000@yahoo.com.br 